\title{
ESTIMATING NUMBERS OF OIL PALM (Elaeis guineensis) POLLEN GRAINS USING IMAGE ANALYSIS AND PROCESSING
}

\section{AGUS DANA PERMANA*; BUDI PERMANA*; BANDUNG SAHARI ${ }^{* *}$; RAMADHANI EKA PUTRA* ${ }^{*}$ and IDA KINASIH ${ }^{\ddagger}$}

\begin{abstract}
Elaeidobius kamerunicus is the most important oil palm pollinator in Indonesia and Malaysia. However, the mechanism and efficiency of pollen transfer by this weevil are clearly not understood. The lack of study on pollination process in oil palm (Elaeis guineensis) is mostly caused by difficulties in pollen counting due to their small size. Most of the counting was conducted manually which is prone to mistakes, required extensive training, and time-consuming. The aim of this study is to provide a novel technique for counting pollen that is rapid, consistent, and efficient with a comparable accuracy to manual counting. Male and female of E. kamerunicus were collected from male and female oil palm inflorescences $(N=60)$. Extracted pollen were placed and distributed in a flat microscope slide separated by designated observation chambers. Images of each chamber were captured as a JPEG format and analysed by ImageJ. Multiple macros were constructed for image processing steps to obtain the pollen numbers. Comparison with manual counting using paired T-test, Pearson's correlation and linear regression showed a high similarity between both methods.
\end{abstract}

Keywords: Elaeis guineensis, Elaeidobius kamerunicus, pollen counting, image processing, ImageJ.

Date received: 18 February 2015; Sent for revision: 19 June 2015; Received in final form: 3 August 2017; Accepted: 4 August 2017.

\section{INTRODUCTION}

One of the major concerns in oil palm (Elaeis guineensis Jacq.) plantation is poor fruit set due to limited pollination. Therefore, in 1981, the oil palm weevil (Elaeidobius kamerunicus) was introduced to address this problem. Subsequently, there has been many reports corroborated that the insect significantly improved fruit set (Syed et al., 1982; Harun and Noor, 2002). This success story has stimulated many studies on the field of pollination biology of oil palm (Sipayung and Lubis, 1987; Dhileepan, 1994; Poinar et al., 2002; Eardley et al.,

* School of Life Sciences and Technology, Institut Teknologi Bandung, Jalan Ganesha, 40132 Bandung, West Java, Indonesia. E-mail: ramdhani@sith.itb.ac.id

** Plant Protection Laboratory, Research and Development, PT Astra Agro Lestari Tbk, Kumai, Indonesia.

\pm Department of Biology, Faculty of Science and Technology, Universitas Islam Negeri Sunan Gunung Djati, 40132 Bandung, West Java, Indonesia.
2006; Purba et al., 2012). Nevertheless, most of these studies only focused on the correlation between the presence of E. kamerunicus and oil palm yield, while the mechanism and the main role of this weevil on pollen transfer remain unclear. For this, we need such a method which can provide rapid, yet precise estimation of the numbers of pollen produced by the plant and how it is distributed by E. kamerunicus. Quantification of pollen would provide critical information to understand of the male reproductive function (Kearns and Inouye, 1993), fitness of different plant morphs (Harder and Barrett, 1993), and crucial to understand the number of pollen grains that is removed and carried by pollinators (Thomson and Goodell, 2001; Adler and Irwin, 2006).

Study on pollen deposition rate by pollinators requires two crucial steps: (1) pollen extraction from pollinator's body and (2) pollen counting from the obtained samples. Pollen separation techniques have been developed extensively by applying several types of solvent, gel, and detergent 
solution (Bernhardt, 2005; Costa and Yang, 2009). Though, these techniques mostly suitable for large insects, rather than small insects like oil palm weevil. Furthermore, pollen counting was usually performed using a haemocytometer (ChinchillaLópez and Richardson, 1991; Dhileepan, 1992; Prada et al., 1998). This method could estimate the total number of pollen grains by extracting data from sub-sample counting. However, application of this method requires special training, time-consuming and prone to disproportionate pollen settling on grids, especially for the large pollen grains are large, leading to erroneous estimates (Kannely, 2005). Alternatively, pollen numbers are counted manually based on photographed pollen. However, this method is labour intensive and consequently prone to human error. Electronic counters, which utilise electric currents to determine the presence of particles offers a faster counting process. Unfortunately, this type of counter could not discriminate debris particles from pollens (Kearns and Inouye, 1993). This problem later was solved by further development and application of laserbased counter for pollen counting (Kawashima et al., 2007). However, high operational cost impedes its operation by frequent users.

Therefore, it is necessary to develop a simple method that could generate rapid and accurate estimation of pollen numbers from the oil palm. One possibility is to use an image processing tool and analysis program which offer a more accurate, user friendly, and consistent estimation (Bechar et al., 1997; Aronne et al., 2001; Fonseca et al., 2002; Costa and Yang, 2009; Geissman et al., 2013; Mudd and Arathi, 2012). This tool is equipped with a particular computer software to scan pollen images, which previously captured as raw images by a camera. The scanned pollen objects are then counted as separated units (Bechar et al., 1997; Arone et al., 2001).

In this study, we used ImageJ, a free-Java based image analysis software provided by the US National Institute of Health (http://rsbweb.nih. gov/ij/; Rasband, 1997-2000; Schneider et al., 2012). Image J has already applied as a method to estimate numbers of small biological objects such as insect eggs, insect adults, and yeast cells (Mains et al., 2008; Kesavaraju and Dickson, 2012; Choudhry, 2016). Using the similar approach, we also developed a specific image preparation procedure and macro to provide an accurate estimation on the pollen numbers of oil palm.

\section{MATERIAL AND METHODS}

\section{Pollen Preparation for Image Analysis}

In this study, image analysis and processing method were applied to count pollen obtained from the body of E. kamerunicus. Both male and female weevils which carried pollen grains were randomly collected from male and female inflorescences of 7 years old oil palm. Unlike airborne pollen, animaldispersed pollen are normally sticky, which tend to form pollen clumps. Thus, a specific washing method is required to prevent this clump formation prior image analysis. The collected insects were placed into a small sample glass bottle, then washed with $100 \mu \mathrm{KOH} 10 \%$ (w/v). Washing method was performed by a 'pump-suck' technique using a small pipette to dissociate pollen clumps from all parts of the weevil's body.

In order to reduce pollen density, 100-200 $\mu 1$ $\mathrm{KOH}$ was added. The $100-300 \mu \mathrm{l}$ pollen solution was pipetted and dropped onto microscope slide. The slide was divided into smaller sub-sample chambers $\left(0.5 \times 0.5 \times 0.1 \mathrm{~cm}^{3}\right)$ by black Nachi Tape ${ }^{\circledR}$ to maintain accuracy of software analysis (Costa and Yang, 2009). Pollen samples from each E. kamerunicus were distributed into five to thirty chambers to generate images with ideal pollen density.

\section{Image Analysis}

Individual slide was mounted on a stereo microscope for image capturing. A Nikon SMZ 1500 stereomicroscope and Nikon Digital Sight DSFI 1 camera was used to capture pollen images for each chamber. The light source was supplied from the bottom and adjusted to allow an optimal light condition for image analysis. All pictures were processed by NIS Element D 3.1® software and saved as JPEG format.

Prior to analysis, captured images were cropped to remove the edges of each viewing chambers. All debris were eliminated using any photo editor software (in our case we used Photoshop ${ }^{\circledR}$ ) then analysed by Image (Figure 1). The accuracy of pollen analyser macro was determined according to Costa and Yang (2009).

\section{Accuracy and Statistical Analysis}

Data of number of pollens obtained by image analysis were compared with those from manual counting. Data of manual counting obtained using cell counter plugin from ImageJ Plugins-Analyze menu. Results from both counting were compared using paired T-test. Correlation between both data was analysed by Pearson's correlation and linear regression. All statistical analysis was carried out by SPSS 13.

\section{RESULTS AND DISCUSSION}

\section{Compatible Multiple Macro for Oil Palm Pollen Grains Counting}

Every flowering plant has different pollen characters, so that the image processing should be 

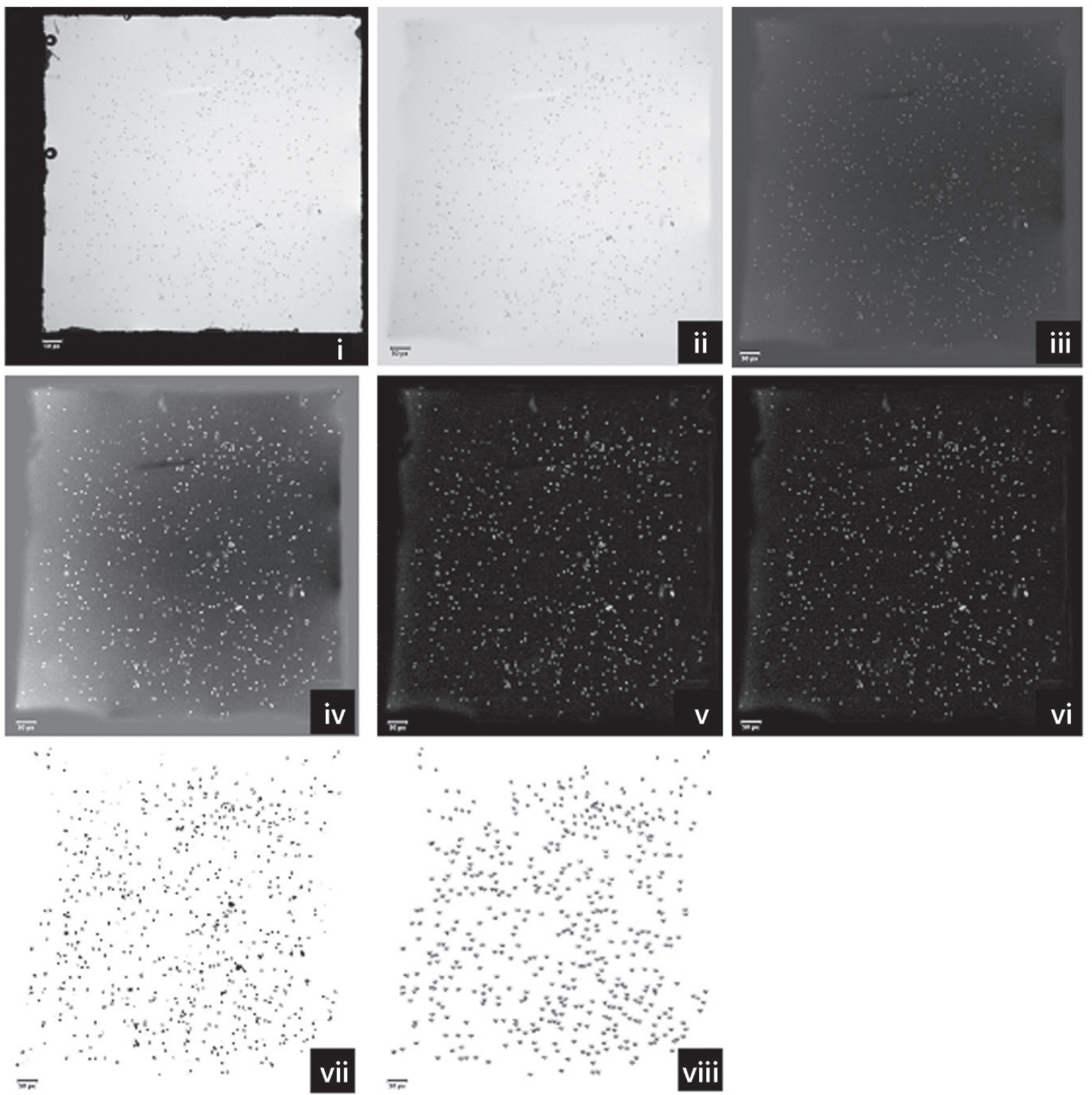

Figure 1. Various images resulting from step-by-step of image processing and analysis using multiple macro on ImageJ program. Serial command (macro) was (i) unprocessed image, (ii) prepared image after cropping and clearing from the debris, (iii) inverted image, (iv) image adjusted for brightness and contrast, (v) image with subtracted background, (vi) 8-bit image, (vii) image adjusted for threshold, (viii) image for particle counting and analysis.

adjusted accordingly. This prompted us to construct procedures for image preparation and macro prior to analysis with ImageJ. The preparation for oil palm pollen processing consisted of six sequential steps: (i) inverting the image to create contrast between dark background and pollen as a light pixels, (ii) setting up brightness and contrast (saturated at 0.15 ) - to increase image contrast, (iii) background substraction (rolling value at $50 \mathrm{px}$ ) to remove the background image, (iv) converting the image to an 8 -bit and adjusting the threshold adjustment at 0 , 55 to transforming the image to binary pixels and improving the proportion of pollen pixels, (v) reinverting to reverse pollen image from light into dark pixels. This step is critical since the software only recognises black pixels as objects to be counted.
The final step was employing a particle analyser (vi), which counted pollens based on its size and circularity (Figure 2).

In order to improve the estimation of pollen number by ImageJ, it is necessary to find correct brightness and contrast, threshold and particle analyser setting. Brightness and contrast should be set be fine-tuned accordingly (Figure $2 b$ ) as low intensity hinders many dark pixels and leads to underestimation (Figure 2b). High contrast might increased the noise resulting in overestimation (Figure 2c). Threshold macro is a command to convert 8-bit image pixels to binary pixels (black and white). The process is based on threshold value that was adjusted previously. A higher value will produce low image conversion while lower value 
might cause too many pixels conversion. Correct value is a necessity as the number of pixels is a basic parameter for pixel identification and pollen object classification.

The final and the most important step is defining the range value for pollen size and its circularity. This value should be adjusted between the minimum and the maximum size also circularity of pollen pixels to reduce overestimation. Any objects with shape range outside this range should be omitted. Therefore, separation process of pollen, by $\mathrm{KOH}$ or detergents, should be considered as the greatest concern as clumped pollens tend to underestimate pollen count. Our study found that the best setting for size and circularity for oil palm pollen ranged from 8 to 40 pixels $^{2}$ and 0.3 to 1.0, respectively.

In order to improve flexibility and speed of image counting, multiple macros, including close command, should be added to batch macro. The constructed batch macro is provided as follow:

macro “Counting of E. guineensis pollen grains (2011)" \{requires ("1.33s");

inputFolder = getDirectory ("Batch Counting!!: Choose your input folder!") :

images $=$ getFileList (inputFolder) ;

for $(i=0 ; i<$ images. length; $i++)\{$

input Path $=$ inputFolder + images [i] ;

open (inputPath);

run ("XXX"); (multiple command)

run ("Close") ;

close ()$;\}$

Based on analysis from 925 images, Image J was able to detect and count pollen grains with high similarity with manual counting (Pearson's $r=0.97$,
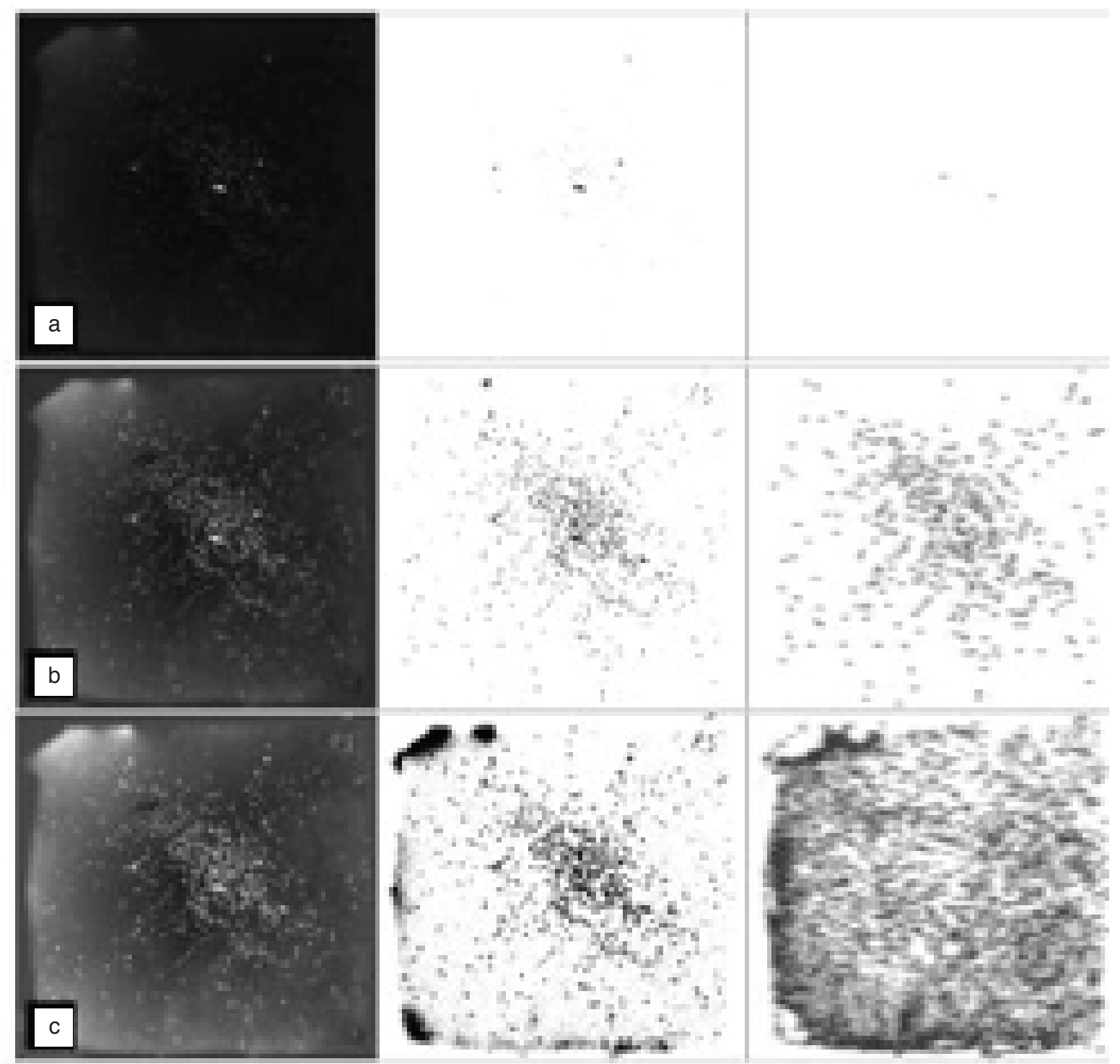

Figure 2. Three sample images representing poor and best macro setting. (a) Low brightness and contrast (0), high threshold (65), narrow range of size (8-30) and circularity (0.3-0.9) lead to under estimation. (b) Middle macro setting $(0.15 ; 55 ; 8-40 ; 0.3-1.00)$ resulted in good prediction. (c) Over brightness and contrast (1), low threshold (20), and wide range of size (0-50) and circularity (0-1) lead to overestimation. 
$\mathrm{P}<0.0001$ ). Linear regression (Figure 3) also showed that image analysis was successful to predict pollen grain, in accordance with Equation $\mathrm{y}=1.556 \mathrm{x}-$ $9.9925\left(r^{2}=0.952\right)$. We also found that only 84 images $(9.08 \%)$ produced estimates less than $75 \%$ of actual number.

The high accuracy of pollen number estimation, in this study was also reported in other studies with different plant families that have different pollen size and shape (Mudd and Arathi, 2012; MacInnis and Forrest, 2017). This flexibility may be beneficial for further application on various oil palm cultivars.

The comparison of pollen prediction by image analysis and manual counting $(\mathrm{N}=15)$ is depicted in Table 1. P-value of paired T-test shows that pollen prediction for each group is not significantly different at $\alpha=0.05$ (two tailed), except for MM group. We believe the difference between manual counting and image analysis found in MM group was caused by high pollen and debris densities on the body of male weevils. Pleura setae present in males weevils provide additional body surface which allowed the smaller debris to contaminate pollen samples (Dhileepan, 1992). Debris might form clusters with pollen which make it difficult for software to delineate individual pollen to give a correct count (Mudd and Arathi, 2012). However,

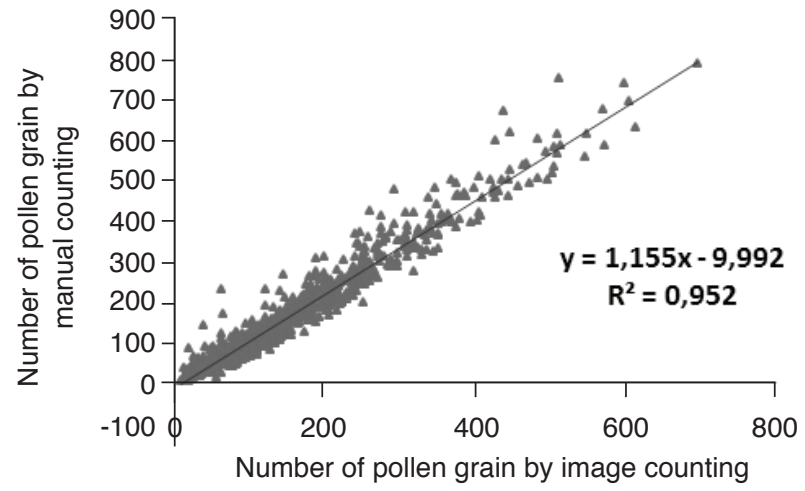

Figure 3. Linear regression between manual counting and image analysis. Manual counting was performed by cell counter plug-in on ImageJ and counting by image analysis was performed by ImageJ with multiple macro $(N=925)$. for many biological studies involving counting of small biological particle, a moderate deviation (lower than 20\%) is often negligible compared to noise generated by other factors (Geissman, 2013). Yet, further studies are needed to: (1) improve method for separation of pollen from debris, (2) improve sensitivity of the pollen detection program, allowing for a better understanding of pollination process in oil palm, and (3) further application of this software to counting small circular objects in oil palm research (i.e. bacterial colony counting, debris counting, etc.) can also be pursued.

\section{CONCLUSION}

In conclusion, image analysis of pollen by ImageJ could be applied as a reliable method for pollen counting. The cost for entire process is considerably low as all processes could be carried out by equipments which are available in any standard biology laboratory and the program is provided as an open source program. Furthermore, image processing using Image reduces the chance of false estimation, ensures a greater consistency on counting and reducing labour requirements for reliable pollen counting.

\section{ACKNOWLEDGEMENT}

We thank Palgunadi and Satyoso for allowing us to use the laboratory and photographic equipment; Agus Widodo, Bargowo Addianto for allowing us to use their personnel; Ali Imran and Jari for helping with manual counting; Prima for her assistance in the field; Erwin for helping with statistical analysis; Ageng Mufti SH for support and critical suggestion in developing macro; Damiran and Hani for helping with research material preparation; Firman, Yusuf, Solihul Amal, Ramadhani Eka, M Kamal Muzzaki, Adeline Prapaisie, Yuvika, Ni Putu Indah, Wahyu Santika for valuable suggestion during research design. This research was partly funded by PT Astra Agro Lestari Tbk and PUPT Grant from Ministry

TABLE 1. COMPARISON OF POLLEN COUNTING BY MANUAL AND IMAGE ANALYSIS METHODS

\begin{tabular}{|c|c|c|c|c|c|}
\hline \multirow[b]{2}{*}{$\begin{array}{l}\text { Sex } \\
(N=15)\end{array}$} & \multirow[b]{2}{*}{ Group } & \multicolumn{3}{|c|}{ Pollen count (mean \pm S.E.) } & \multirow[b]{2}{*}{$\begin{array}{c}\text { P-value } \\
\text { (paired T-test) }\end{array}$} \\
\hline & & $\begin{array}{c}\text { Manual counting } \\
\text { using ImageJ cell } \\
\text { counter plugin }\end{array}$ & $\begin{array}{l}\text { Image analysis } \\
\text { counting by ImageJ } \\
\text { multiple macro }\end{array}$ & $\begin{array}{l}\text { Pearson's } \\
\text { correlation } \\
\text { (r) }\end{array}$ & \\
\hline \multirow[t]{2}{*}{ Male } & $\sigma^{\top}(\mathrm{MM})$ & $5721( \pm 376)$ & $5075( \pm 317)$ & 0.984 & 0.000 \\
\hline & $q(\mathrm{MF})$ & $698( \pm 97)$ & $727( \pm 97)$ & 0.949 & 0.360 \\
\hline \multirow[t]{2}{*}{ Female } & $\sigma^{7}(\mathrm{FM})$ & $3357( \pm 368)$ & $3172( \pm 287)$ & 0.971 & 0.123 \\
\hline & 里 (FF) & $293( \pm 31)$ & $277( \pm 27)$ & 0.96 & 0.112 \\
\hline
\end{tabular}

Note: * MM - male weevil at male inflorescences, MF- male at female inflorescences, FM - female at male inflorescences, FF- Female at female inflorescences. 
of Research, Technology and Higher Education granted to the first author.

\section{REFERENCES}

ADLER, L S and IRWIN, R E (2006). Comparison of pollen transfer dynamics by multiple floral visitors: experiments with pollen and fluorescent dye. Ann. Bot., 97: 141-150.

ARONNE, G; CAVUOTO, D and EDUARDO, P (2001). Classification and counting of fluorescent pollen using an image analysis system. Biotech Histochem., 76: 35-40.

BECHAR, A; GAN-MOR, S; VAKNIN, Y; SHMULEVICH, I; RONEN, B and EISIKOWITCH, D (1997). An image-analysis technique for accurate counting of pollen on stigmas. New Phytol., 137: 639-643.

BERNHARDT, P (2005). Pollen transport and transfer by animal pollinators. Practical Pollination Biology (Dafni, A, Kevan, P G and Husband, B $\mathrm{C}$ eds.). Enviroquest Ltd. Cambridge, Ontario, Canada. p. 371-380.

CHINCHILLA-LÓPEZ, C M and RICHARDSON, D L (1991). Pollinating insects and the pollination of oil palms in Central America. ASD Technical Bulletin, 2: $1-18$.

CHOUDHRY, P (2016). High-throughput method for automated colony and cell counting by digital image analysis based on edge detection. PloS ONE, 11(2): e0148469.

COSTA, C M and YANG, S (2009). Counting pollen grains using readily available, free image processing and analysis software. Ann. Bot., 104(5): 1005-1010.

DHILEEPAN, K (1992). Pollen carrying capacity, pollen loads, pollen transferring ability of the oil palm pollinating weevil Elaeidobius kamerunicus Faust in India. Oleagineux, 47: 55-61.

DHILEEPAN, K (1994). Variation in populations of the introduced pollinating weevil (Elaeidobius kamerunicus) (Coleoptera: Curculionidae) and its impact on fruit set of oil palm (Elaeis guineensis) in India. Bull. Entomol. Res., 84: 477-485.

EARDLEY, C; ROTH, D; CLARKE, C; BUCHMANN, $S$ and GEMMIL, B (2006). Pollinators and Pollination: A Resource Book for Policy and Practice. African Pollinator Initiative, Pretoria, South Africa.

FONSECA, A E; WESTGATE, M E and DOYLE, R T (2002). Application of fluorescence microscopy and image analysis for quantifying dynamics of maize pollen shed. Crop Sci., 42: 2201-2206.

GEISSMAN, Q (2013). OpenCFU, a new free and open-source software to count cell colonies and other circular objects. PLoS ONE, 8(2): e54072.

HARDER, L D and BARRETT, S C H (1993). Pollen removal from tristylous Pontederia cordata: effects of anther position and pollinator specialization. Ecology, 74: 1059-1072.

HARUN, M H and NOOR, M R M D (2002). Fruit set and oil palm components. J. Oil Palm Res. Vol. 14(2): 24-33.

KANNELY, A (2005). Preparation and quantification of entomophilous pollen using sonication and an area counting technique. Madron o, 52: 267-269.

KAWASHIMA, S; CLOT, B; FUJTA, T; TAKAHASHI, $Y$ and NAKAMURA, K (2007). An algorithm and a device for counting airborne pollen automatically using laser optics. Atmos. Environ., 41: 7987-7993.

KEARNS, C A and INOUYE, D W (1993). Techniques for Pollination Biologists. Niwot, CO: University Press of Colorado.

KESAVARAJU, B and DICKSON, S (2012). New technique to count mosquito adults: using ImageJ software to estimate number of mosquito adults in a trap. J. Am. Mosq. Control. Assoc., 28(4): 330-333.

MAINS, J W; MERCER, D R and DOBSON, S L (2008). Digital image analysis to estimate numbers of aedes eggs oviposited in containers. J. Am. Mosq. Control. Assoc., 24(4): 496-501.

MACINNIS, G and FORREST, J R K (2017). Quantifying pollen deposition with macro photography and 'stigmagraphs'. J. Poll. Ecol., 20(2): 13-21.

MUDD, S J and ARATHI, H S (2012). Image analysis protocol for detecting and counting viable and inviable pollen grains. J. Plant Stud., 1(2): 158-167.

POINAR, G O; JACKSON, T A; BELL, N L and WAHID M B (2002). Elaolenchus parthenonema, sp. (Nematoda; Sphaerularioidea: Anandanematidae n. fam.) parasitic in the palm pollinating weevil Elaeidobius kamerunicus Faust, with a phylogenetic synopsis of the Sphaerularioidea Lubbock, 1861. Syst. Parasitol., 52: 219-225.

PRADA, M; MOLINA, D; VILLAROEL, D; BARRIOS, R and DIAZ, A (1998). Efectividad de Dos Especies del Género Elaeidobius (Coleoptera: 
Curculionidae) Como Polinizadores En Palma Aceitera. Bioagro, 10(1): 3-10.

PURBA, $\mathrm{R} \mathrm{Y}$; ROZZIANSHA, $\mathrm{T}$ A $\mathrm{P}$ and PANGARIBUAN, Y (2012). Strategies to improve effectiveness of pollination and productivity on early mature oil palm. Proc. of the Fourth IOPRI$M P O B$ International Seminar: Existing and Emerging of Oil Palm Pests and Diseases - Advance in Research and Management.

SCHNEIDER, C A; RASBAND, W S and ELICEIRI, K W (2012). NIH Image to ImageJ: 25 years of image analysis. Nat. Methods, 9: 671-675.
SYED, R A; LAW, I H and CORLEY, R H V (1982). Insect pollination of oil palm: introduction, establishment and pollinating efficiency of Elaeidobius kamerunicus in Malaysia. The Planter, 58: 547-561.

SIPAYUNG, A and LUBIS, A U (1987). Dampak pelepasan Elaeidobius kamerunicus Faust di Indonesia. Bulletin Pusat Penelitian Marihat, 7(2): 7-14.

THOMSON, J D and GOODELL, K (2001). Pollen removal and deposition by honeybee and bumblebee visitors to apple and almond flowers. J. Appl. Ecol. 38: 1032-1044. 